\title{
Ameliorative potential of Alstonia scholaris (Linn.) R. Br. against chronic constriction injury-induced neuropathic pain in rats
}

\author{
Hasandeep Singh ${ }^{1}$, Rohit Arora ${ }^{2}$, Saroj Arora ${ }^{2}$ and Balbir Singh ${ }^{1 *}$
}

\begin{abstract}
Background: Alstonia scholaris commonly known as 'Saptaparni' is an Indian traditional medicinal plant used in Ayurveda. It is commonly used to treat various disorders like asthma, bronchitis, diarrhea, dysentery and malaria. In folklore medicine the milky juice of the plant is applied on wounds and ulcers to treat pain, ear ache and also in rheumatic pains.
\end{abstract}

Aim: The present study was designed to investigate the potential of A. scholaris R. Br. in chronic constriction injury of sciatic nerve $(\mathrm{CCl})$ induced neuropathic pain in rats.

Methods: Peripheral neuropathy was induced by chronic constriction injury of sciatic nerve. The behavioral parameters like mechanical and thermal hyperalgesia and cold allodynia were assessed on the $14^{\text {th }}$ day. Tissue parameters like total protein, thiobarbituric acid reactive substances, reduced glutathione, myeloperoxidase, total calcium and TNF-a were assessed to check biochemical changes. Chloroform and methanol extract of $A$. scholaris leaves (100 and $200 \mathrm{mg} / \mathrm{kg}$ ) and pregabalin (10 mg/kg, as positive control) were administered orally for 14 consecutive days starting from the day of surgery.

Results: CCI resulted in significant development of mechanical hyperalgesia, heat hyperalgesia and cold allodynia along with alteration in the biochemical changes. Administration of methanol extract at $200 \mathrm{mg} / \mathrm{kg}$ significantly attenuated the $\mathrm{CCl}$ induced change in nociceptive threshold and biochemical changes which was comparable to that of pregabalin. The high-performance liquid chromatography (HPLC) of the bioactive methanol extract revealed the presence of different types of flavonoids such as gallic acid, catechin, epicatechin, ellagic acid and kaempferol, in which kaempferol was observed to be in higher concentration.

Conclusion: Methanol extract (200 mg/kg) of A. scholaris showed the ameliorative effect in CCl induced neuropathic pain which may be due to the presence of kaempferol and attributed to its anti-oxidative and anti-inflammatory properties.

\section{Background}

Neuropathic pain as stated by International Association for the Study of Pain is a pain generated by an abrasion or dysfunction in the nervous system [1,2]. Generally, an abnormal sensation (dysesthesia), enhanced response to noxious stimuli (hyperalgesia) and pain due to hypo responsive stimuli (allodynia) are characteristics of neuropathic pain [3]. Patients with diabetes, AIDS, cancer, stroke and spinal cord injury are noted to

\footnotetext{
* Correspondence: balbir_gndu@yahoo.com

'Department of Pharmaceutical Sciences, Guru Nanak Dev University,

Amritsar 143005, India

Full list of author information is available at the end of the article
}

demonstrate peripheral neuropathic pain [4]. Although, current drugs available for the effective management of neuropathic pain such as tricyclic antidepressants, antiepileptic drugs, cannabinoid receptor agonists and sodium channel blockers are effective, but, their usage is associated with many side effects [5]. On the other hand, traditional medicines provide a sigh of relief due to their unprecedented biological activities with least adverse effects.

Among an array of traditional plants, Alstonia scholaris (Linn.) R. Br. (Family Apocyanaceae), popularly known as "Saptaparni" in Hindi or the 'Indian devil tree' has been 
used in folk medicines for treating diarrhea, dysentery, malaria, fever and cardiac as well as respiratory problems $[6,7]$. In folklore medicine, the milky juice of plant is applied on injuries and ulcers to treat pain including rheumatic pains [7]. Moreover, the plant afforded protection in various models of algesia and inflammation, including, acetic acid-induced writhing, formalin test and air pouch model in rodents [8]. Most of these pharmacotherapeutic effects of $A$. scholaris have been attributed to the presence of various phytoconstituents such as alkaloids, coumarins, iridoids, flavonoids, leucoanthocyanines, steroids, tannins, phenolics and saponins [9]. As traditional reports show that plant is useful in treating the normal and rheumatic pains and according to pharmacological reports the plant also exhibits anti-inflammatory and analgesic activities. Therefore, the plant $A$. scholaris was evaluated against neuropathic pain using rat model.

\section{Methods}

\section{Plant material}

Fresh leaves of A. scholaris were collected in September from the botanical garden, Guru Nanak Dev University, GNDU, Amritsar. Taxonomic identification of plant was done by Department of Botanical and Environmental Sciences, GNDU, Amritsar (voucher specimen No. 520). The leaves of $A$. scholaris were shade dried and reduced to coarse powder.

\section{Drugs and chemicals}

One,1,3,3 tetra methoxy propane (Sigma Aldrich, Bangalore, India), reduced glutathione (GSH) (Loba Chemie, Mumbai, India) were used in the present study. Tumor necrosis factor- $\alpha$ (TNF- $\alpha)$ assay kit was procured from RayBiotech, Norcross, USA and total protein kit was procured from Span Diagnostics Ltd., Gujrat, India. Other reagents used in the present study were of analytical grade.

\section{Extraction}

Soxhlet extraction of powdered plant material was carried out using different solvents with increasing order of polarity viz petroleum ether, chloroform and methanol. The obtained extracts were air-dried at room temperature to evaporate the solvent. Finally, the aqueous extract was obtained by digesting marc with distilled water for $24 \mathrm{~h}$. Each extract was concentrated under pressure using rotatory evaporator (IKA Works Inc., North America). Dried concentrated extracts were finally weighed and their percentage yield was calculated. The final product was stored at $4{ }^{\circ} \mathrm{C}$.

\section{Experimental animals}

For animal studies and reporting, the authors adhered to guidelines of Committee for the Purpose of Control and
Supervision of Experiments on Animals (CPCSEA), Ministry of Environment and Forest, Government of India, and ARRIVE guidelines. In present study, Wistar rats having body weight 250-300 g (procured from Indian Institute of Integrated Medicine, Jammu) were employed. Institutional Animal Ethics Committee of GNDU, Amritsar duly approved the animal experiments (Approval No. 226/CPCSEA/2013/07). Free access to rodent feed, water and necessary living environment was ensured in central animal facility of GNDU.

\section{Induction of peripheral neuropathy by chronic constriction injury $(\mathrm{CCl})$}

Standardized model of chronic constriction injuryinduced peripheral neuropathy was employed in present study [10]. In brief, rats were anaesthetized using chloral hydrate at $300 \mathrm{mg} / \mathrm{kg}$ and common sciatic nerve in left hind paw was exposed. Four loose ligatures of 4-0 chromic gut with $1 \mathrm{~mm}$ spacing were placed around the sciatic nerve. The muscle and skin were sutured in two separate layers. Sham surgery involved the exposure of sciatic nerve without inducing any lesion. The sterile conditions were ensured during surgery. All the treatments were given after CCI and animals survived for 2 weeks post-surgery.

\section{Experimental protocol}

Forty-eight (48) animals were randomly assigned into 8 groups, each comprising 6 rats. The extracts were suspended in $0.5 \%$ carboxymethyl cellulose and were administered orally in rats.

\section{Group I (Normal control)}

No surgery was performed in rats.

\section{Group II (Sham control)}

Rats were subjected to surgical procedure to expose common sciatic nerve without inducing any injury to the nerve.

\section{Group III (CCI control)}

Rats were subjected to CCI to induce peripheral neuropathic pain.

\section{Group IV (Pregabalin) Standard drug}

Rats with CCI were treated with Pregabalin $(10 \mathrm{mg} / \mathrm{kg}$, oral) for 14 consecutive days post-surgery.

\section{Group V-VI (Chloroform extract (CE), 100 and $200 \mathrm{mg} / \mathrm{kg}$ )}

After sciatic nerve injury, the chloroform extract (100 and $200 \mathrm{mg} / \mathrm{kg}$, oral) was administered in rats for 14 days.

\section{Group VII-VIII (Methanol extract (ME), 100 and} $200 \mathrm{mg} / \mathrm{kg}$ )

Methanol extract of A. scholaris (100 and $200 \mathrm{mg} /$ $\mathrm{kg}$, oral) was administered for 14 consecutive days in rats with $\mathrm{CCI}$. 


\section{Behavioral examination}

\section{Assessment of mechanical hyperalgesia}

Pin prick test was employed to assess mechanical hyperalgesia in rats as described earlier [11]. In rats, the sharp end of bent needle was touched on lateral plantar surface of both hind paws with an intensity just sufficient to produce a reflex withdrawal. The paw withdrawal duration was recorded using a stopwatch with cut-off time of $20 \mathrm{~s}$.

\section{Assessment of thermal hyperalgesia}

Thermal nociceptive threshold, an index of thermal-hyperalgesia was measured using hot plate method [12]. Rats were placed on Eddy's hot plate $\left(52 \pm 1{ }^{\circ} \mathrm{C}\right)$ and withdrawal latency of paw (licking of the paw), was recorded. A cut-off time of $20 \mathrm{~s}$ was selected.

\section{Assessment of cold allodynia}

The reactivity towards chemical induced cold stimulus was determined by using established methods in rodents [13]. Briefly, the rats were placed on wired mesh grid, acetone was applied on plantar surface of their hind paw and withdrawal response was measured (in seconds). A cut-off time of $60 \mathrm{~s}$ was used in this protocol.

\section{Biochemical estimations}

After 2 weeks of surgery, the rats were euthanized by cervical dislocation. The sciatic nerve tissue was excised and homogenized $(10 \% \mathrm{w} / \mathrm{v})$ using $0.1 \mathrm{M}$ Tris buffer (pH-7.4). The contents were centrifuged $(2000 \times g)$ at $4{ }^{\circ} \mathrm{C}$ for $10 \mathrm{~min}$. The clear supernatant so obtained was used for quantification of TNF- $\alpha$, thiobarbituric acid reactive substances (TBARS), reduced glutathione $(\mathrm{GSH})$ and total calcium content. Tissue surrounding the sciatic nerve was homogenized, followed by centrifugation at $5000 \times g$ for $10 \mathrm{~min}$. The pellet obtained was used for quantification of myeloperoxidase activity.

\section{Estimation of TNF-a}

Enzyme-linked immunosorbent assay based kit was used to estimate TNF- $\alpha$ levels in nerve homogenate. Total protein in nerve tissue was quantified using commercially available kit. Level of TNF- $\alpha$ was reported as $\mathrm{pg} / \mathrm{mg}$ of protein.

\section{Estimation of thio-barbituric acid reactive substances (TBARS)}

The lipid peroxides in nerve tissue were quantified in terms of TBARS using established method [14]. The absorbance was measured spectrophotometrically at $532 \mathrm{~nm}$. Results were expressed as nanomoles per $\mathrm{mg}$ of protein.

\section{Estimation of GSH}

GSH level in tissue was determined using method of Beutler et al. [15]. The GSH level was expressed as micrograms of reduced glutathione per mg of protein.

\section{Estimation of total calcium}

Total calcium level in sciatic nerve was measured using atomic absorption spectrophotometer as detailed by Severnghaus and Ferrebee [16]. Total calcium level was expressed as parts per million per mg of protein.

\section{Estimation of myeloperoxidase (MPO) activity}

The MPO activity was measured using method described by Krawisz et al. [17]. The MPO activity was expressed as units per gram of tissue.

\section{Chromatographic analysis}

The TLC based fingerprinting profile of bioactive compounds in methanol extract was carried out using a precoated plates (Merck, Germany). Chloroform and methanol were used as solvent system in 99:1 ratio. Further, the methanol extract $(1 \mathrm{mg} / \mathrm{ml})$ was subjected to HPLC analysis. HPLC machine was fitted with RP-18 column $(250 \mathrm{~mm} \times 4 \mathrm{~mm}) 5 \mu \mathrm{m}$, an efficient degasser and a photodiode array detector (PDA) (Shimadzu Analytical (India) Pvt. Ltd.). Gradient elution was carried out using methanol and $0.1 \%$ acetic acid at a flow rate of $1 \mathrm{ml} / \mathrm{min}$.

\section{Statistical analysis}

The behavioral parameters (nonparametric data) were analyzed using Kruskal-Wallis test followed by Dunn's post hoc test. Data for biochemical estimations were analyzed using one-way analysis of variance followed by Tukey's posthoc test (Sigma stat version- 3.5 software). All the values were expressed as mean \pm standard error of mean (S.E.M.). $P \leq 0.05$ was considered to be statistically significant.

\section{Results}

There was no significant change observed between control and sham groups. Therefore, all the comparisons were made with respect to control group.

\section{Effect of chloroform and methanol extract of $A$. scholaris} on mechanical hyperalgesia in $\mathrm{CCl}$ induced neuropathy CCI led to mechanical hyperalgesia demonstrated by the significant increase in withdrawal threshold of hind paw in pinprick test as compared to control rats. Treatment of rats with pregabalin significantly ameliorated the paw withdrawal reflex. Administration of chloroform and methanol extracts of $A$. scholaris (100 and $200 \mathrm{mg} / \mathrm{kg}$ ) markedly attenuated the CCI-induced increase in nociceptive threshold. Methanol extract exhibited better protection than chloroform extract against CCI-induced neuropathy in rats (Fig. 1). 


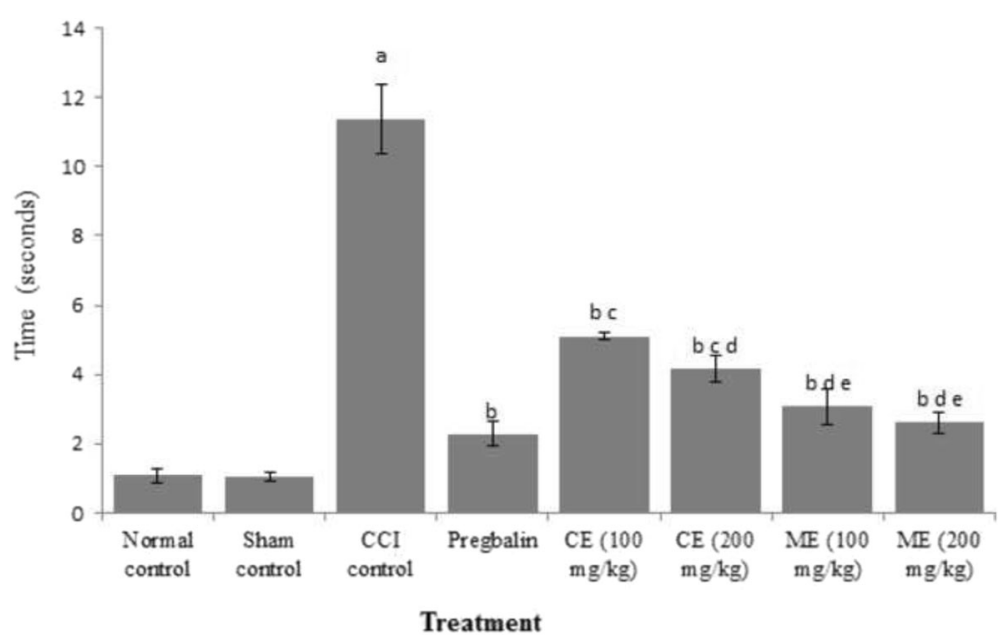

Fig. 1 Effect of chloroform and methanol extracts on mechanical hyperalgesia in chronic constriction injury induced neuropathy. Values are expressed as mean \pm S.E.M. $\mathrm{a}=p<0.05 \mathrm{Vs}$ control; $\mathrm{b}=p<0.05 \mathrm{Vs} \mathrm{CCl} ; \mathrm{c}=p<0.05 \mathrm{Vs}$ pregabalin; $\mathrm{d}=p<0.05 \mathrm{Vs}$ chloroform extract (100 mg/kg); $\mathrm{e}=p<0.05 \mathrm{Vs}$ chloroform extract $(200 \mathrm{mg} / \mathrm{kg})$

Effect of chloroform and methanol extract of $A$. scholaris on thermal hyperalgesia and cold allodynia in CCI-induced neuropathy

The constriction of sciatic nerve resulted in a significant thermal hyperalgesia and cold allodynia, which was ameliorated by pregabalin treatment in rats. Administration of chloroform and methanol extracts (100 and $200 \mathrm{mg} / \mathrm{kg}$ ) attenuated the CCI-induced reduction in nociceptive threshold for thermal hyperalgesia and cold allodynia (Figs. 2 and 3).

\section{Effect of chloroform and methanol extract of $A$. scholaris} on oxidative stress markers

Increase in lipid peroxides (measured in terms of TBARS and decrease in GSH) levels was observed in
CCI group as compared to control group. Pregabalin significantly ameliorated the oxidative stress in rats. Treatment of animals with chloroform and methanol extract of A. scholaris (100 and $200 \mathrm{mg} / \mathrm{kg}$ ) attenuated CCI-induced increase in TBARS and decrease in GSH levels. Moreover, the methanol extract afforded better protection than chloroform extract in rats. (Figs. 4 and 5).

Effect of chloroform and methanol extract of $A$. scholaris on total calcium and inflammatory markers in $\mathrm{CCl}$ induced neuropathy

CCI resulted in a significant increase in total calcium, TNF- $\alpha$ and myeloperoxidase (MPO) in sciatic nerve of $\mathrm{CCI}$ rats as compared to control group. Pregabalin

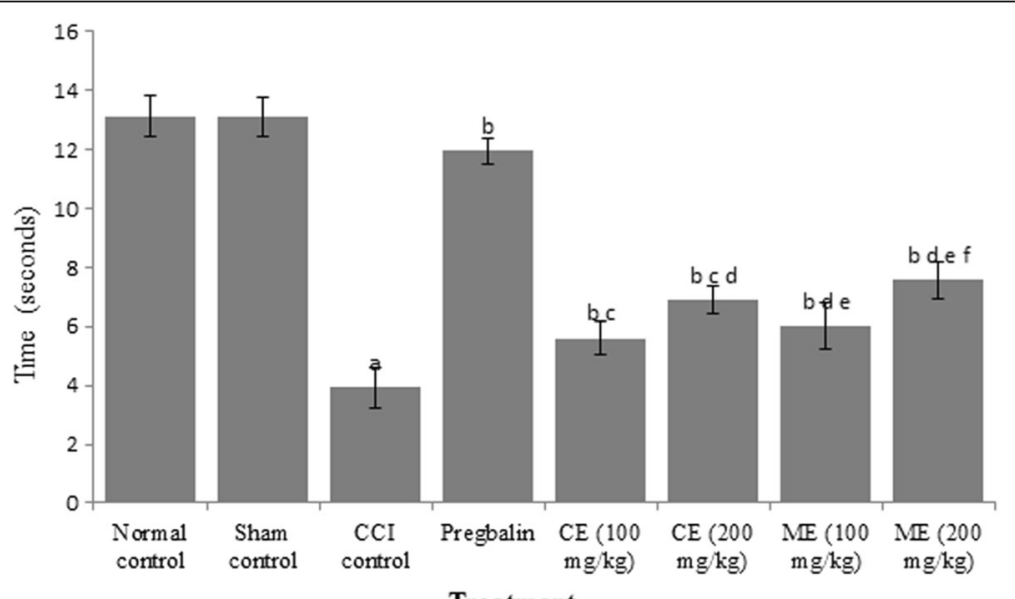

Treatment

Fig. 2 Effect of chloroform and methanol extracts on heat hyperalgesia in chronic constriction injury induced neuropathy. Values are expressed as mean \pm S.E.M. $\mathrm{a}=p<0.05 \mathrm{Vs}$ control; $\mathrm{b}=p<0.05 \mathrm{Vs} \mathrm{CCl} ; \mathrm{c}=p<0.05 \mathrm{Vs}$ pregabalin; $\mathrm{d}=p<0.05 \mathrm{Vs}$ chloroform extract $(100 \mathrm{mg} / \mathrm{kg}) ; \mathrm{e}=p<0.05$ Vs chloroform extract $(200 \mathrm{mg} / \mathrm{kg})$ 


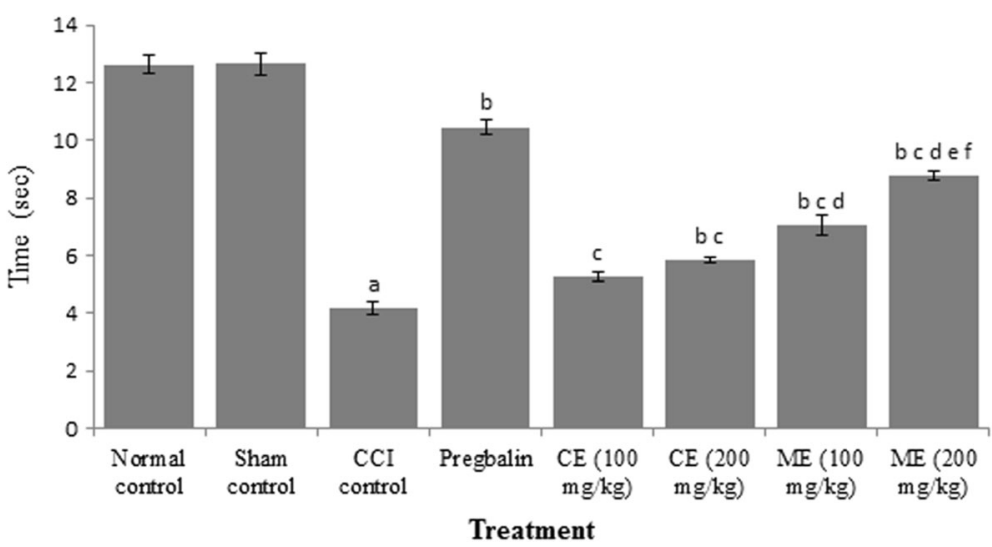

Fig. 3 Effect of chloroform and methanol extracts on cold allodynia in chronic constriction injury induced neuropathy. Values are expressed as mean \pm S.E.M. $\mathrm{a}=p<0.05 \mathrm{Vs}$ control; $\mathrm{b}=p<0.05 \mathrm{Vs} C \mathrm{Cl} ; \mathrm{c}=p<0.05 \mathrm{Vs}$ pregabalin; $\mathrm{d}=p<0.05 \mathrm{Vs}$ chloroform extract $(100 \mathrm{mg} / \mathrm{kg}) ; \mathrm{e}=p<0.05 \mathrm{Vs}$ chloroform extract $(200 \mathrm{mg} / \mathrm{kg}) ; f=p<0.05 \mathrm{Vs}$ Methanol extract $(100 \mathrm{mg} / \mathrm{kg})$

treatment markedly reduced total calcium and inflammatory cytokines. Administration of chloroform and methanol extract (100 and $200 \mathrm{mg} / \mathrm{kg}$ ) obviated CCI induced increase in total calcium, TNF- $\alpha$ and myeloperoxidase activity. Treatment with methanol extract witnessed better anti-inflammatory activity than chloroform extract in rats. (Figs. 6, 7 and 8).

\section{Chromatographic analysis}

The TLC based fingerprinting profile of bioactive constituents in methanol extract showed the presence of 5 spots (Table 1). The results of high performance liquid chromatogram of methanol extract are shown in Table 2.

\section{Discussion}

Chronic constriction induced sciatic nerve injury is one of the widely-employed models to evaluate potential agents for the management of neuropathic pain in rodents [9]. The CCI-induced neuropathic pain is observed in various clinical situations such as arthroplasty, complex regional pain syndrome, fracture as well as stroke [18]. Various cellular events such as alteration in the calcium homeostasis, release of pro-inflammatory mediators (TNF- $\alpha$ and MPO) and generation of reactive oxygen species lead to neuronal damage and neuropathic pain $[19,20]$. The sustained activation of peripheral nociceptive receptor leads to hypersensitization of secondary neurons and central nervous system [21].

In the present investigation, the ameliorative effect of A. scholaris in CCI induced neuropathic pain had been observed. CCI resulted in mechanical hyperalgesia, thermal hyperalgesia and cold allodynia demonstrated by pin prick method, hot plate method and acetone drop test, respectively. The change in pain threshold in the said

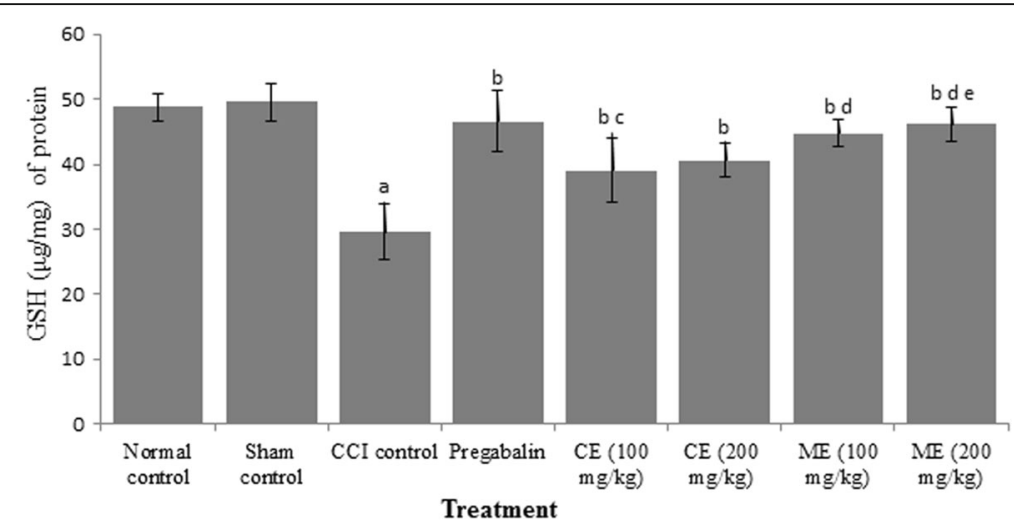

Fig. 4 Effect of chloroform and methanol extracts on reduced glutathione activity in chronic constriction injury induced neuropathy. Values are expressed as mean \pm S.E.M. $\mathrm{a}=p<0.05 \mathrm{Vs}$ control; $\mathrm{b}=p<0.05 \mathrm{Vs} \mathrm{CCl} ; \mathrm{c}=p<0.05$ Vs pregabalin; $\mathrm{d}=p<0.05 \mathrm{Vs}$ chloroform extract (100 mg/kg); $\mathrm{e}=p<0.05 \mathrm{Vs}$ chloroform extract $(200 \mathrm{mg} / \mathrm{kg})$ 


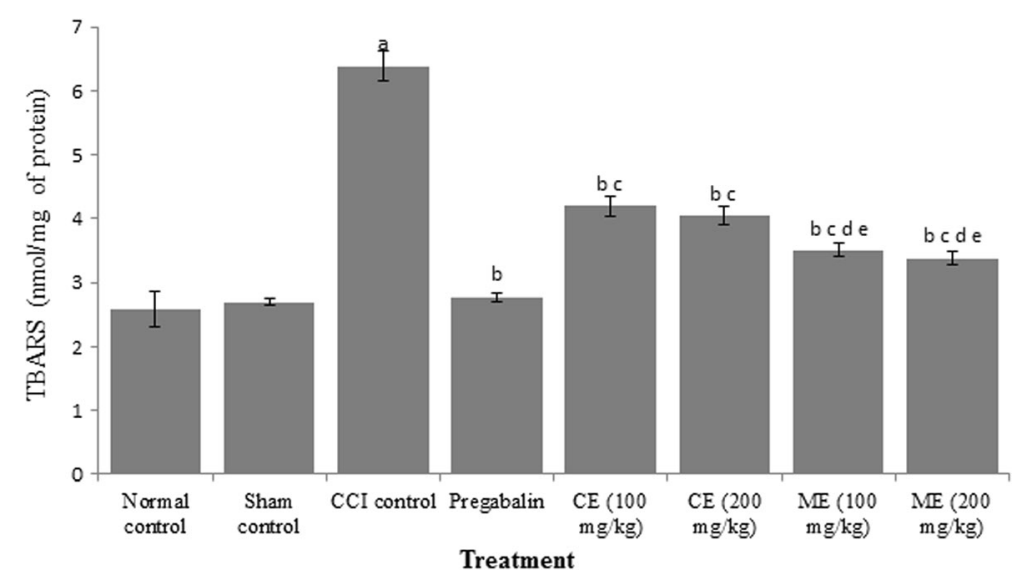

Fig. 5 Effect of chloroform and methanol extracts on thio-barbituric acid reactive substances (TBARS) in chronic constriction injury induced neuropathy Values are expressed as mean \pm S.E.M. $\mathrm{a}=p<0.05$ Vs control; $\mathrm{b}=p<0.05$ Vs $C C l ; c=p<0.05$ Vs pregabalin; $\mathrm{d}=p<0.05$ Vs chloroform extract $(100 \mathrm{mg} / \mathrm{kg})$; $\mathrm{e}=p<0.05 \mathrm{Vs}$ chloroform extract $(200 \mathrm{mg} / \mathrm{kg})$

models indicated successful induction of peripheral neuropathy in rats. It is documented that these behavioral alterations start on $3^{\text {rd }}$ day after surgery and attain their peak in 2 weeks [22]. The chronic treatment with chloroform and methanol extracts of A. scholaris (100 and $200 \mathrm{mg} / \mathrm{kg}$ ) for 14 days significantly increased nociceptive threshold as observed with mechanical hyperalgesia, heat hyperalgesia and cold allodynia test. However, A. scholaris methanol extract $(200 \mathrm{mg} / \mathrm{kg})$ have been observed to have better pharmacotherapeutic effects in comparison to chloroform extract for management of CCI induced neuropathic pain.

Increased levels of reactive oxygen species (ROS) in the body cause cell damage or cell death. Therefore, removal of excessive ROS is important to restore normal conditions. It is a proven fact that ROS are one of the major perpetrators in the induction and progression of neuropathic pain [23]. Marked increase in TBARS and decrease in GSH level in sciatic nerve demonstrated oxidative stress in CCI group, which is in accordance with previous findings. Treatment with chloroform and methanol extracts (100 and $200 \mathrm{mg} / \mathrm{kg}$ ) for 14 days resulted in marked attenuation of neuropathic pain and oxidative stress in animals. However, methanol extract at $200 \mathrm{mg} / \mathrm{kg}$ showed better protection against oxidative stress. Our results are supported by the fact that other free radical scavengers such as phenyl-N-tert-butylnitrone showed profound reduction of spinal nerve ligation-induced mechanical allodynia in rats. Furthermore, spin trap agents like 5,5-dimethylpyrroline- $\mathrm{N}$ -

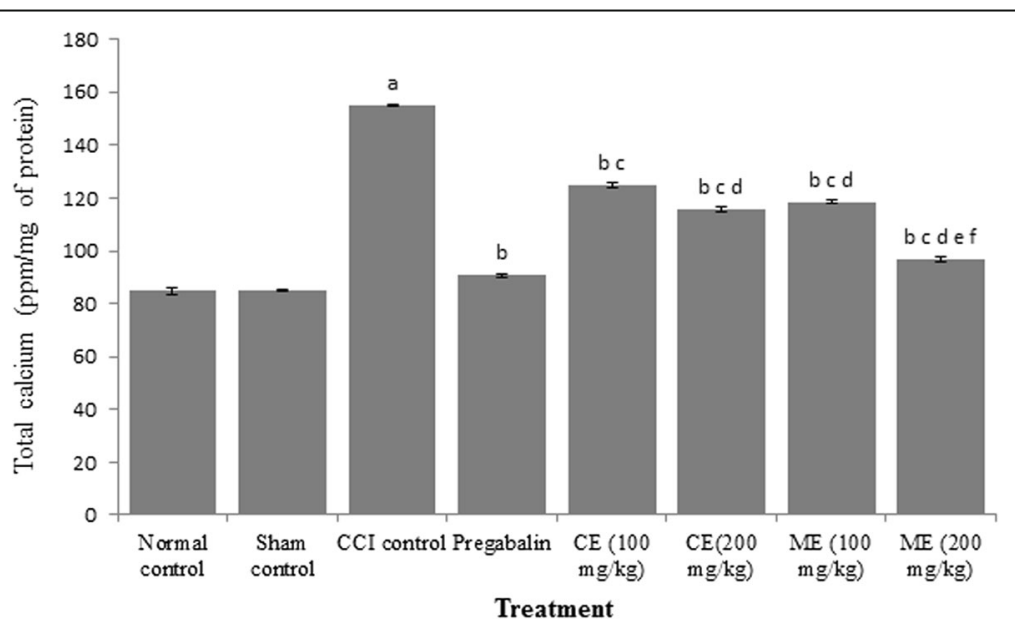

Fig. 6 Effect of chloroform and methanol extracts on calcium levels in chronic constriction injury induced neuropathy. Values are expressed as mean \pm S.E.M. $\mathrm{a}=p<0.05 \mathrm{Vs}$ control; $\mathrm{b}=p<0.05 \mathrm{Vs} C \mathrm{Cl} ; \mathrm{c}=p<0.05 \mathrm{Vs}$ pregabalin; $\mathrm{d}=p<0.05 \mathrm{Vs}$ chloroform extract $(100 \mathrm{mg} / \mathrm{kg}) ; \mathrm{e}=p<0.05 \mathrm{Vs}$ chloroform extract $(200 \mathrm{mg} / \mathrm{kg}) ; \mathrm{f}=p<0.05 \mathrm{Vs}$ Methanol extract $(100 \mathrm{mg} / \mathrm{kg})$ 


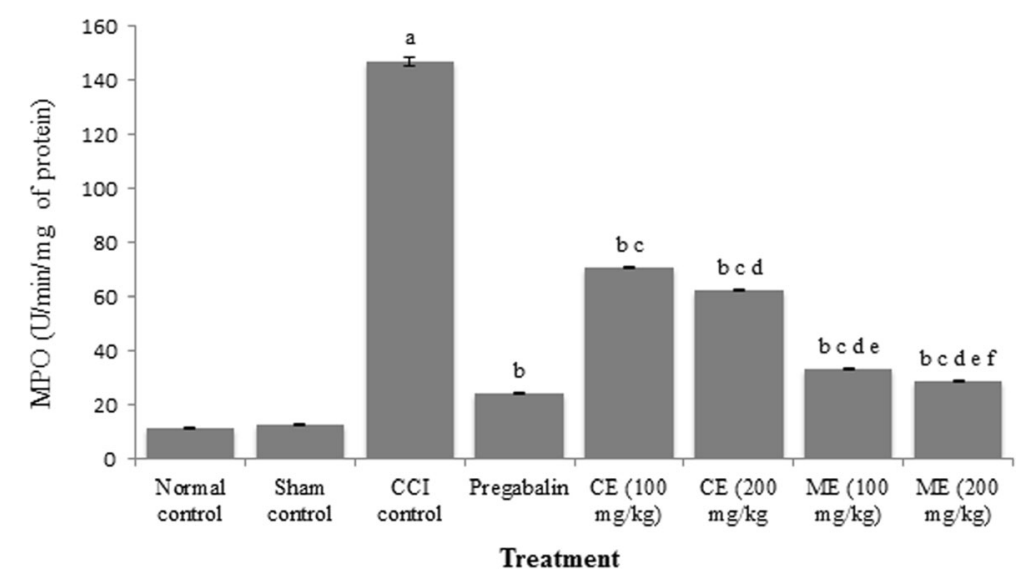

Fig. 7 Effect of chloroform and methanol extracts on myeloperoxidase activity in chronic constriction injury induced neuropathy. Values are expressed as mean \pm S.E.M. $\mathrm{a}=p<0.05 \mathrm{Vs}$ control; $\mathrm{b}=p<0.05 \mathrm{Vs} C \mathrm{Cl} ; \mathrm{c}=p<0.05 \mathrm{Vs}$ pregabalin; $\mathrm{d}=p<0.05 \mathrm{Vs}$ chloroform extract (100 mg/kg); $\mathrm{e}=p<0.05 \mathrm{Vs}$ chloroform extract $(200 \mathrm{mg} / \mathrm{kg}) ; \mathrm{f}=p<0.05 \mathrm{Vs}$ Methanol extract $(100 \mathrm{mg} / \mathrm{kg})$

oxide and nitroso benzene demonstrated similar effects thereby highlighting the detrimental role in the development of neuropathic pain [24].

We observed a significant increase in inflammatory cytokine including TNF- $\alpha$ and myeloperoxidase activity in sciatic nerve. The CCI-induced neuropathy has also been associated with significant inflammation as assessed by marked increase in MPO and TNF- $\alpha$ levels. The neutrophils are known to release MPO and rise in MPO activity is a well-defined marker for inflammation [25]. Various research groups have demonstrated a significant association between oxidative stress and inflammation in CCI-induced neuropathic pain [26, 27]. It is reported that inflammatory mediators such as bradykinin, prostaglandins, TNF- $\alpha$, interleukin- $1 \beta$ are involved in induction as well as progression of neuropathic pain $[28,29]$. Calcium ion accumulation has been well documented to play an important role in post-traumatic axotomy, CCI, anti HIV drugs and vincristine induced neuropathy [30-32]. Another interesting finding of the study was restored calcium accumulation in the sciatic nerve in animals having CCI induced neuropathic pain. Muthuraman and Singh have reported significant increase in total calcium in sciatic nerve in CCI group than the control group. Similar results are witnessed in our studies. Intracellular accumulation of calcium triggers various biochemical changes including hyper-excitability, activation of phospholipases, proteolytic enzymes. These biochemical changes result in cellular damage and death [33, 34]. In the neuronal tissues, calcium induced activation of calpains has been reported to degrade axonal cytoskeleton and thus resulting in axonal degeneration [35]. Administration of chloroform and methanol extracts

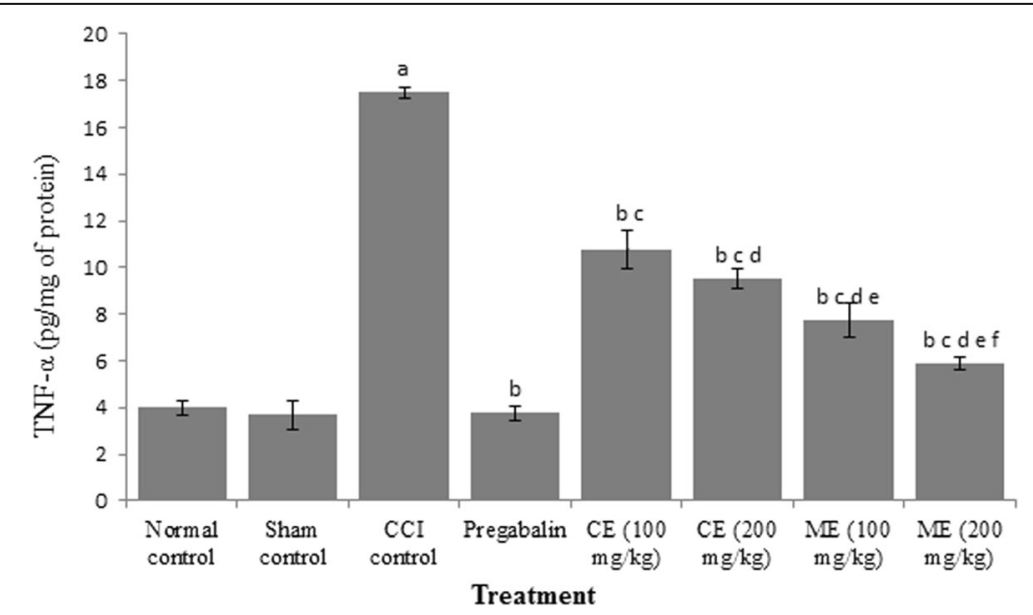

Fig. 8 Effect of chloroform and methanol extracts on TNF-a levels in chronic constriction injury induced neuropathy. Values are expressed as mean \pm S.E.M. $\mathrm{a}=p<0.05 \mathrm{Vs}$ control; $\mathrm{b}=p<0.05 \mathrm{Vs} \mathrm{CCl} ; \mathrm{c}=p<0.05 \mathrm{Vs}$ pregabalin; $\mathrm{d}=p<0.05 \mathrm{Vs}$ chloroform extract $(100 \mathrm{mg} / \mathrm{kg}) ; \mathrm{e}=p<0.05 \mathrm{Vs}$ chloroform extract $(200 \mathrm{mg} / \mathrm{kg}) ; \mathrm{f}=p<0.05 \mathrm{Vs}$ Methanol extract $(100 \mathrm{mg} / \mathrm{kg})$ 
Table 1 TLC fingerprinting profile of methanol extract of $A$. scholaris using chloroform and methanol as mobile phase (99:1). The values indicate the $R_{f}$ values of the separated bands

\begin{tabular}{lllc}
\hline Sr. No. of Resolving Bands & UV $254 \mathrm{~nm}$ & UV 366 & Under day light \\
\hline 1. & - & - & 0.25 \\
2. & - & - & 0.34 \\
3. & - & - & 0.75 \\
4. & - & - & 0.87 \\
5. & - & - & 0.93 \\
\hline
\end{tabular}

(100 and $200 \mathrm{mg} / \mathrm{kg}$ ) for 14 days resulted in marked attenuation of inflammatory cytokines and calcium levels. Thus, decrease calcium level may be another molecular mechanism which may explain the ameliorative effect of $A$. scholaris on for the management of CCI-induced neuropathic pain. Interestingly methanol extract of A. scholaris at $200 \mathrm{mg} / \mathrm{kg}$ showed better antioxidant and anti-inflammatory activity than chloroform extract. On the same lines administration of methanol extract attenuated neuropathic pain better than chloroform extract. Our results suggest that antioxidant and anti-inflammatory activity of the methanol extract of $A$. scholaris accounts for its neuroprotective activity.

Flavonoids are secondary plant metabolites and possess significant antioxidant activity. Various flavonoids such as myrcetin, rutin, quercetin and kaempferol are noted to relieve neuropathic pain induced by various culprit agents [36-43]. Antioxidant potential of $A$. scholaris pertaining to presence of various polyphenols such as gallic acid, catechin, epicatechin, ellagic acid and kaempferol may explain its significant ameliorative effect in CCI induced neuropathic pain. Thus, significant antioxidant potential of $A$. scholaris might be responsible for improvement in behavioral, and biochemical outcomes in $\mathrm{CCI}$ induced neuropathic pain in rats.

However, further studies are required to consolidate our findings using other models of neuropathic pain.

Table 2 Compounds revealed in high performance liquid chromatography at different retention time

\begin{tabular}{|c|c|c|c|c|c|c|c|}
\hline Peak\# & Ret. Time & Area & Heigh & Conc. & Unit & Mark & Name \\
\hline 1. & 1.894 & 125,395 & 4092 & 0.000 & & & \\
\hline 2. & 2.733 & 16,307 & 812 & 1.144 & $\mathrm{mg} / \mathrm{L}$ & V & Gallic acid \\
\hline 3. & 3.559 & 1715 & 114 & 0.718 & $\mathrm{mg} / \mathrm{L}$ & & Catechin \\
\hline 4. & 5.673 & 1636 & 151 & 0.430 & $\mathrm{mg} / \mathrm{L}$ & & Epicatechin \\
\hline 5. & 15.684 & 135,192 & 4469 & 29.733 & $\mathrm{mg} / \mathrm{L}$ & & Ellagic acid \\
\hline 6. & 15.887 & 49,079 & 4773 & 0.000 & & V & \\
\hline 7. & 16.204 & 266,914 & 5061 & 42.677 & $\mathrm{mg} / \mathrm{L}$ & V & \\
\hline 8. & 17.224 & 235,946 & 3191 & 100.534 & $\mathrm{mg} / \mathrm{L}$ & V & Kaempferol \\
\hline Total & & 832,184 & 22,663 & & & & \\
\hline
\end{tabular}

\section{Conclusion}

The present study concluded that $A$. scholaris substantially ameliorated CCI induced neuropathic pain in rats. A. scholaris treatment reduced calcium deposition in nerve, which could be the major mechanism responsible for its neuroprotective potential besides inhibiting the inflammatory cytokines and ROS production.

\section{Abbreviations \\ $\%$ : Percentage; ${ }^{\circ} \mathrm{C}$ : Degree centigrade; ANOVA: Analysis of variance; \\ CCl: Chronic Constriction Injury; $\mathrm{cm}$ : Centimeter; \\ CMC: Carboxymethylcellulose; CNS: Central nervous system; DTNB: \\ 5, 5'-Dithio, bis (2-nitro benzoic acd); g: Gram; GSH: Glutathione; \\ HETAB: Hexadecyl Trimethyl Ammonium Bromide; i.p: Intraperitoneal; \\ IASP: International Association for the study of Pain; mg: Milligram; \\ ml: Millilitre; MPO: Myeloperoxidase; nmol: Nanomole; p.o.: Per oral; \\ S.E.M: Standard error of mean; sec: Second; $\mu$ l: Microlitre}

\section{Acknowledgements}

The authors duly acknowledge the financial assistance provided under the university with potential for excellence by University Grants Commission, India to Guru Nanak Dev University, Amritsar, Punjab (India). The authors are thankful to the Department of Pharmaceutical Sciences, Guru Nanak Dev University, Amritsar, Punjab (India) for supporting this study and providing technical facilities for this work.

\section{Funding}

No.

Availability of data and materials

All the data has been presented in the manuscript.

\section{Authors' contributions}

HS performed experimental work. RA helped in HPLC analysis. Corresponding author Dr. BS developed the idea and designed the experimental work. Dr. SA helped in data analysis. All authors discussed the results, commented on the manuscript and prepared the discussion part accordingly. All authors read and approved the final manuscript.

\section{Competing interests}

There is no conflict of interest associated with this publication.

\section{Consent for publication}

Not applicable.

Ethics approval and consent to participate

The experimental protocol was duly approved by Institutional Animal Ethics Committee (IAEC) (Reg. No. 226/CPCSEA/2013/07). All the experiments were done as per the rules of CPSEA.

\section{Author details}

${ }^{1}$ Department of Pharmaceutical Sciences, Guru Nanak Dev University, Amritsar 143005, India. ${ }^{2}$ Department of Botanical and Environmental Sciences, Guru Nanak Dev University, Amritsar 143005, India.

Received: 21 August 2016 Accepted: 11 January 2017

Published online: 19 January 2017

\section{References}

1. Moalem G, Tracey DJ. Immune and inflammatory mechanisms in neuropathic pain. Brain Res Rev. 2006;51(2):240-64

2. Merskey $\mathrm{H}$, Bogduk N. Classification of chronic pain. Descriptions of chronic pain syndromes and definitions of pain terms. Seattle: IASP Press; 1994. p. 222.

3. Burakgazi AZ, Messersmith W, Vaidya D, Hauer P, Hoke A, Polydefkis M. Longitudinal assessment of oxaliplatin-induced neuropathy. Neurology. 2011;77:980-6. 
4. Werhagen LB, Hultling $C N$, Molander $C$. Neuropathic pain after traumatic spinal cord injury relations to gender, spinal level, completeness and age at the time of injury. Spinal Cord. 2004;42:665-73.

5. Namaka M, Gramlich CR, Ruhlen D, Melanson M, Sutton I, Major J. A treatment algorithm for neuropathic pain. Clin Ther. 2004;26:951-79.

6. Nandkarni AK, Nadkarni KM. The Indian Materia Medica, with Ayurvedic, Unani and Home Remedies. Vol 1. Bombay: Popular Prakashan; 1976. p. 80-83.

7. Arulmozhi S, Mazumder PM, Narayan LS, Thakurdesai PA. In vitro antioxidant and free radical scavenging activity of fractions from alstonia scholaris Linn. RBr Int J PharmTech Res. 2010;2:18-25.

8. Shang JH, Cai XH, Feng T, Zhao YL, Wang JK, Zhang LY, Yan M, Luo XD. Pharmacological evaluation of alstonia scholaris: anti-inflammatory and analgesic effects. J Ethnol. 2010;129(2):174-81.

9. Khyade MS, Vaikos NP. Phytochemical and antibacterial properties of leaves of alstonia scholaris R. Br. Afr J Biotechnol. 2009;8:6434-6.

10. Bennett GJ, Xie YK. A peripheral mononeuropathy in rat that produces disorders of pain sensation like those seen in man. Pain. 1998:33:87-107.

11. Erichsen HK, Blackburn-Munro G. Pharmacological characterization of the spared nerve injury model of neuropathic pain. Pain. 2002;98:151-61.

12. Andreas B, Rainer KWS. Inhibitory avoidance, pain reactivity and plus maze behaviour in wistar rats with high versus low rearing activity. Physiol Behav. 2005;84:387-96

13. Choi Y, Yoon YW, Na HS, Kim SH, Chung JM. Behavioral signs of ongoing pain and cold cold allodynia in a rat model of neuropathy pain. Pain. 1994:59:369-76.

14. Okhawa H, Ohishi N, Yagi K. Assay for lipid peroxidation in animal tissue by thiobarbituric acid reaction. Anal Biochem. 1979;95:351-8.

15. Beutler E, Duron O, Kelly BM. Improved method for the determination of blood glutathione. J Lab Clin Med. 1963;6:882-8.

16. Severinghaus JW, Ferrebee JW. Calcium determination by flame photometry; methods for serum, urine, and other fluids. J Biol Chem. 1950;187:621-30.

17. Krawisz JE, Sharon P, Stenson WF. Qualitative assay for acute intestinal inflammation based on myeloperoxidase activity. Gastroenterol. 1984;87:1344-50.

18. Herlyn P, Muller-Hilke B, Wendt M, Hecker M, Mittlmeier T, Gradl G. Frequencies of polymorphisms in cytokines, neurotransmitters and adrenergic receptors in patients with complex regional pain syndrome type I after distal radial fracture. Clin J Pain. 2010;26:175-81.

19. Marchand F, Perretti M, Mcmahon SB. Role of immune system in chronic pain. Nat Rev Neurosci. 2005;6:521-32

20. Li F, Fang L, Huang S, Yang Z, Nandi J, Thomas S, Chen C, Camporesi E. Hyperbaric oxygenation therapy alleviates chronic constrictive injuryinduced neuropathic pain and reduces tumor necrosis factor-alpha production. Anesth Anal. 2011;113:626-33.

21. Woolf CJ, Mannion RJ. Neuropathic pain, aetiology, symptoms, mechanisms and management. Lancet. 1999;353:1959-64.

22. Jaggi AS, Singh N. Exploring the potential of telmisartan in chronic constriction injury- induced neuropathic pain in rats. Eur J Pharmacol. 2011;667:215-21.

23. Naik AK, Tandan SK, Dudhgaonkar SP, Jadhav SH, Kataria M, Prakash VR. Role of oxidative stress in pathophysiology of peripheral neuropathy and modulation by N-acetyl-L-cysteine in rats. Eur J Pain. 2006;10:573-9.

24. Kim HK, Park SK, Zhou L, Taglialatela G, Chung K, Coggeshall RE, Chung JM. Reactive oxygen species (ROS) play an important role in a rat model of neuropathic pain. Pain. 2004;111:116-34.

25. Posadas I, Bucci M, Roviewzo F, Rossi A, Parente L, Sautebin L, Cirino G. Carrageenan-induced mouse paw odema is biphasic age weight dependent and displays different nitric oxide cyclooxygenase-2 expression. Br J Pharmacol. 2004;142:331-8.

26. Daemen $M$, Kurvers $H$, Bullens $P$, Barendse $G$, Vankleef $M$, Van den Wildenberg F. Neurogenic inflammation and reflex sympathetic dystrophy in vivo and in vitro assessment in an experimental model. Acta Orthopaedica Belg. 1998;64:441-7.

27. Labuda CJ, Donahue R, Fuchs PN. Enhanced formalin nociceptive responses following 1,5 nerve ligation in the rat reveals neuropathy induced inflammatory hyperalgesia. Pain. 2001;94:59-63.

28. Cui JG, Holmin S, Mathiesen T, Meyerson BA, Linderoth B. Possible role of inflammatory mediators in tactile hypersensitivity in rat models of mono neuropathy. Pain. 2000;88:239-48

29. Schafers M, Svensson Cl, Sommer C, Sorkin LS. Tumour necrosis factor alpha induces mechanical allodynia after spinal nerve ligation by activation of p38 MAPK in primary sensory neurons. J Neurosci. 2003;23:2517-21.
30. Tari C, Fournier N, Briand C, Ducet G, Crevat A. Action of vinca alkaloids on calcium movements through mitochondrial membrane. Pharmacol Res Commun. 1986;18:519-28.

31. Sylvain A, Hassan B, Brice CE, Mohammad A, Veronique M, Denis G, Jean V, Frederique S. Axotomy-induced expression of calcium activated chloride current in sub populations of mouse dorsal root ganglion neurons. J Neurophysiol. 2003;90:3764-73.

32. Siau C, Bennett G. Dysregulation of neuronal calcium homeostatis in chemotherapy evoked painful peripheral neuropathy. Anesth Analg. 2006; 102:1485-90.

33. Xie X, Barrett JN. Membrane resealing in cultured rats septal neurons after neurite transection: evidence for enhancement by calcium triggered protease activity and cytoskeletal disassembly. J Neurosci. 1991;11:3257-67.

34. Young W. Role of calcium in central nervous system injuries. J Neurotrauma. 1992:9:S9-S25.

35. Glass JD, Culver DG, Levey Al, Nash NR. Very early activation of m-calpain in peripheral nerve during wallerian degeneration. J Neurol Sci. 2002;196:9-20.

36. Taylor LP, Grotewold E. Flavonoids as developmental regulators. Curr Opin Plant Biol. 2005;8:317-23.

37. Hertog M, Hollman P. Potential health effects of the dietary flavonol quercetin. Eur J Clin Nutr. 1996;50(2):63-71.

38. Straubinger $M$, Jezussek $M$, Waibel $R$, Winterhalter $P$. Two kaempferol sophorosides from crocus sativus. Nat Prod Lett. 1997;10:213-6.

39. Kubo I, Kinst-Hori I. Flavonols from saffron flower: tyrosinase inhibitory activity and inhibition mechanism. J Agric Food Chem. 1999;47:4121-5.

40. Hagenacker T, Hillebrand I, Wissmann A, Busselberg D, Schafers M. Anti-allodynic effect of the flavonoid myricetin in a rat model of neuropathic pain: involvement of p38 and protein kinase $\mathrm{C}$ mediated modulation of $\mathrm{Ca}^{2+}$ channels. Eur J Pain. 2010;14:992-8

41. Meotti FC, Luiz AP, Pizzolatti MG, Kassuya CAL, Calixto JB, Santos ARS. Analysis of the antinociceptive effect of the flavonoid myricitrin. Evidence for a role of the L-arginine nitric oxide and protein kinase $C$ pathways. J Pharmacol Exp Ther. 2006:316:789-96.

42. Azevedo MI, Pereira AF, Nogueira RB, Rolim FE, Brito GAC, Wong DVT, Lima-Junior RCP, Ribeiro De RA, Vale ML. The antioxidant effects of the flavonoids rutin and quercetin inhibit oxaliplatin-induced chronic painful peripheral neuropathy. Mol Pain. 2013:9:53.

43. Abo-Salem OM. Kaempferol attenuates the development of diabetic neuropathic pain in mice: possible anti-inflammatory and anti-oxidant mechanisms. Maced J Med Sci. 2014;7(3):424-30.

\section{Submit your next manuscript to BioMed Central and we will help you at every step:}

- We accept pre-submission inquiries

- Our selector tool helps you to find the most relevant journal

- We provide round the clock customer support

- Convenient online submission

- Thorough peer review

- Inclusion in PubMed and all major indexing services

- Maximum visibility for your research

Submit your manuscript at www.biomedcentral.com/submit
) Biomed Central 